\title{
Microstructural Design of Sensor Materials Using the Core-shell Concept
}

\author{
C. R. Bowen, ${ }^{a}$ A. W. Tavernor, ${ }^{b *}$ J. Luo ${ }^{a}$ and R. Stevens ${ }^{a}$ \\ ${ }^{a}$ School of Materials Science, University of Bath, Bath BA2 7AY, UK \\ ${ }^{b}$ School of Materials, University of Leeds, Leeds LS2 9JT, UK
}

(Received 15 May 1998; accepted 10 August 1998)

\begin{abstract}
An yttria stabilised zirconia which exhibits a coreshell microstructure was investigated as a method to produce a zirconia with high ionic conductivity and improved thermal shock resistance. Zirconia grains consist of an outer shell of tetragonal zirconia with an inner core of monoclinic phase zirconia. Impedance spectroscopy was used to identify the effect of processing conditions on the grain boundary and grain interior ionic conductivity. At optimised processing conditions the grain boundary conductivity was found to be significantly higher than conventional yttria stabilised zirconia. A small improvement in thermal shock resistance of the material was also observed. (C) 1998 Elsevier Science Limited. All rights reserved
\end{abstract}

Keywords: $\mathrm{ZrO}_{2}$, ionic conductivity, thermal shock resistance, microstructure-final, impedance.

\section{Introduction}

There is considerable interest in zirconia materials in applications requiring high oxygen ion conductivity, such as oxygen sensors and solid oxide fuel cells. ${ }^{1}$ Most ionic conductivity measurements have concentrated on fully (CSZ) or partially stabilised zirconia (PSZ). Tetragonal zirconia polycrystalline (TZP) materials have received some attention due to their high conductivity at moderate temperatures, combined with improved mechanical properties. ${ }^{2,3}$

At moderate temperatures $\left(<600^{\circ} \mathrm{C}\right)$ the grain interior of TZP has a lower resistivity when compared to fully or partially stabilised zirconia. ${ }^{4}$ However, TZP has a higher total ionic resistivity

*To whom correspondence should be addressed. Fax: + 44(0)1225-826098; e-mail: msscrb@materials.bath.ac.uk due to a continuous grain boundary glassy phase which increases the grain boundary resistivity. In CSZ or PSZ the grain boundary resistivity is decreased by increasing the grain size of the material (the grain boundary per unit volume is decreased) or by producing easy paths for conduction (no continuous secondary grain boundary phase). For TZP an increase in grain size is less desirable as this leads to destabillsation (formation of the monoclinic phase) which is detrimental to the mechanical properties and ionic conductivity. A lowering in grain boundary resistivity in TZP is often achieved by decreasing the impurity levels. In addition, TZP materials also have limited thermal shock resistance compared to PSZ which contains microcracks, enhancing thermal shock resistance.

Ionic conductivity of zirconia materials is often measured by impedance spectroscopy (IS); a technique introduced by Bauerle. ${ }^{5}$ The principle of impedance spectroscopy is that the impedance of a material is measured over a wide range of frequency. Different regions (grain interior and grain boundaries) or different phases in the material are characterised by both resistive $(R)$ and capacitive $(C)$ components which each have a characteristic relaxation time, $\tau=R C$. Presenting the impedance data over the measured frequency range in an appropriate form makes it possible to resolve and measure the value of $R$ and $C$ for each region of the microstructure.

As impedance spectroscopy enables measurement of the grain interior and grain boundary resistance and capacitance, it is an important tool for the characterisation of ionic conductivity of zirconia. Grain boundaries have a large impact on the properties of the polycrystalline ceramic materials, such as Y-TZP, and a detailed knowledge of grain boundary behaviour is essential for the optimisation of material properties.

Recent work on yttria coated zirconia powders has produced a 'core-shell microstructure' in yttria 
stabilised TZP whereby grains consist of on outer shell of stabilised tetragonal zirconia into which the yttria has diffused and a pure monoclinic core which contains no stabiliser. ${ }^{6}$ This microstructure is said to improve the hydrothermal degradation of the material. ${ }^{7}$ The aim of this paper is to investigate whether this core-shell microstructure would also combine the properties of high ionic conductivity (outer tetragonal shell) and good thermal shock resistance (monoclinic core). This approach to microstructural design to improve sensor material properties is a somewhat novel concept for the materials scientist, although it is found in $\mathrm{BaTiO}_{3}$ ceramics. ${ }^{8}$

\section{Experimental}

The starting powder consisted of Tioxide Specialties zirconia powder with a crystal size of $\sim 70 \mathrm{~nm}$ (prepared by plasma oxidation of $\mathrm{ZrCl}_{4}$ ) coated with 2.9 mole $\%$ yttria as a stabiliser. The TZP material was prepared by sintering cold pressed pellets using a variety of sintering profiles for $1 \mathrm{~h}$.

Complex electrical impedance measurements were carried out on sample discs $11 \mathrm{~mm}$ diameter and $1.5 \mathrm{~mm}$ thick with platinum electrodes fired on each surface. Impedance measurements were carried out in the frequency range $0 \cdot 1 \mathrm{~Hz}$ to $500 \mathrm{kHz}$ using a Solatron 1260 Frequency Response Analyser at temperatures in the range $250-450^{\circ} \mathrm{C}$. Resistance values were corrected for specimen geometry. Thermal shock measurements were investigated by quenching samples in water at $25^{\circ} \mathrm{C}$ and subsequently strength testing using a biaxial ball-on-ring arrangement.

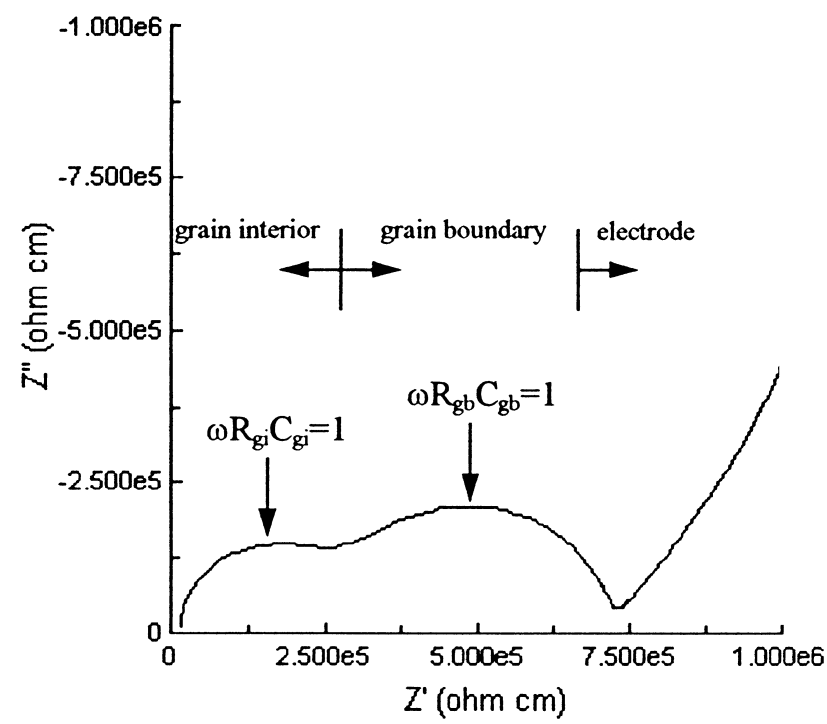

\section{Results}

\subsection{Ionic conductivity}

In the temperature range $250-450^{\circ} \mathrm{C}$ the grain interior and grain boundary semi-circles are clearly resolved in the complex impedance spectrum as there is a sufficiently large difference in the time constants

$$
\tau_{1}=R_{\mathrm{gi}} C_{\mathrm{g}} \text { and } \tau_{2}=R_{\mathrm{gb}} C_{\mathrm{gb}}
$$

where

$R_{\mathrm{gi}}=$ grain interior resistance $(\Omega)$

$C_{\mathrm{gi}}=$ grain interior capacitance $(\mathrm{F})$

$R_{\mathrm{gb}}=$ grain boundary resistance $(\Omega)$

$C_{\mathrm{gb}}=$ grain boundary capacitance $(\mathrm{F})$

Figure 1 shows a typical impedance spectrum of $\mathrm{Y}-\mathrm{TZP}$ at $300^{\circ} \mathrm{C}$ (sintered at $1400^{\circ} \mathrm{C} 1 \mathrm{~h}$ ). The high frequency semicircle $\left(R_{\mathrm{gi}}, C_{\mathrm{gi}}\right)$ is due to the grain interior region and the low frequency curve $\left(R_{\mathrm{gb}}, C_{\mathrm{gb}}\right)$ is associated with that of the grain boundary area. The third semicircle, which is only partly observed, is the electrode response. The presence of an electrode arc suggests that conductivity is ionic, as would be expected for $\mathrm{ZrO}_{2}$ at the temperatures employed.

The resistive and capacitive components of the grain interior and grain boundary were calculated from the impedance spectra using equivalent circuit fitting. The equivalent circuit is shown in Fig. 2 as proposed by Bauerle, ${ }^{5}$ which has been widely used to interpret IS data for zirconia materials. The radius of each semi circle is representative of the resistance of the grain interior and grain boundary phase respectively, whereas the maxima of each curve is a function of the condition $\omega R C=1$, where $\omega=2 \pi f$ and $f$ is known.
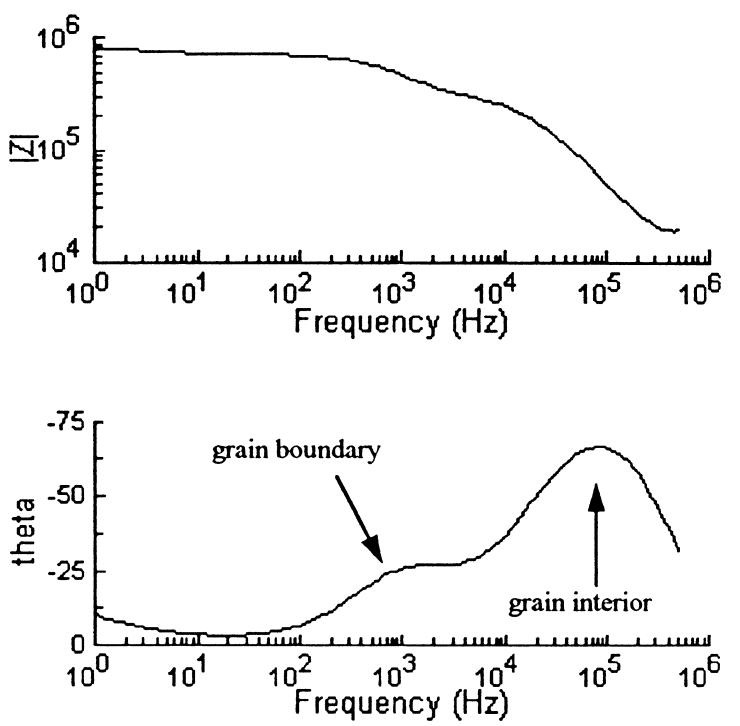

Fig. 1. Impedance data of $\mathrm{Y}-\mathrm{TZP}$ material at $300^{\circ} \mathrm{C}\left(1400^{\circ} \mathrm{C} / 1 \mathrm{~h}\right)|\mathrm{Z}|=$ modulus of impedance, theta $(\theta)=$ phase angle, $\operatorname{Re}(\mathbf{Z}) \equiv \mathbf{Z}^{\prime}=|\mathbf{Z}| \cos \theta$ and $\operatorname{Im}(\mathbf{Z}) \equiv \mathbf{Z}^{\prime \prime}=|\mathbf{Z}| \sin \theta$. 


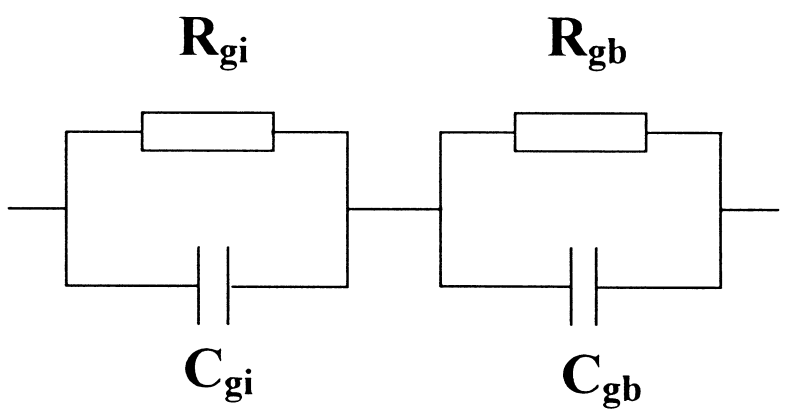

Fig. 2. Equivalent circuit representation of grain interior and grain boundary frequency response in zirconia.

The overall resistance of the material is given by the combination of the grain interior and grain boundary resistances. This analysis highlights the singular advantage of impedance spectroscopy, allowing the individual contributions of grain interior and grain boundary phase to the ionic conductivity of the material to be estimated as a function of relevant variables such a temperature in which case further data such as activation energies can be determined.

\subsubsection{Variation of grain interior resistivity with processing temperature}

The variation of grain interior resistivity $\left(R_{\mathrm{gi}}\right)$ with sintering temperature is summarised in Table 1 and Fig. 3. It can be seen that the graph consists of three regions. Initially, $R_{\mathrm{gi}}$ decreases with increasing sintering temperature (region I), presumably due to the greater degree of zirconia stabilisation by yttria to the tetragonal phase $\left(R_{\text {tetragonal }}<R_{\text {monoclinic }}\right)$.

In the sintering temperature range $1400-1550^{\circ} \mathrm{C}$ (region II) there is a slow decrease in $R_{\mathrm{gi}}$ as there is no large change in the chemical composition of the grain interiors. $R_{\mathrm{gi}}$ is at a minimum at $1550^{\circ} \mathrm{C}$ and is similar in magnitude to reported data (Table 1).

Sintering above $1650^{\circ} \mathrm{C}$ (region III) causes a large increase in $R_{\mathrm{gi}}$ due to destabilisation of the zirconia and the formation of monoclinic zirconia. This

Table 1. $R_{\mathrm{gi}}(\mathrm{k} \Omega \mathrm{cm})$ for $\mathrm{Y}-\mathrm{TSP}$ materials sintered at various temperatures

\begin{tabular}{lcccccc}
\hline & \multicolumn{7}{c}{$\begin{array}{c}\text { Sintering temperature } \\
\left({ }^{\circ} \mathrm{C} \text { for } 1 \mathrm{~h}\right)\end{array}$} \\
\hline $\begin{array}{l}\text { Measurement } \\
\text { temperature } \\
{[\mathrm{T} /(\mathrm{K})]}\end{array}$ & 1300 & 1375 & 1400 & 1550 & 1650 & 1750 \\
\hline 523 & & & & & & \\
548 & 4880 & 2440 & 1790 & 1380 & 2520 & 8190 \\
573 & 1770 & 889 & 680 & 557 & 950 & 3300 \\
& 686 & 358 & 275 & 208 & 386 & 1230 \\
603 & & & & $130-170^{a}$ & & \\
633 & 241 & 127 & 100 & $83 \cdot 0$ & 141 & 492 \\
673 & 92.9 & $48 \cdot 2$ & $37 \cdot 3$ & $26 \cdot 6$ & $53 \cdot 3$ & 158 \\
723 & 30.0 & 13.4 & $10 \cdot 2$ & 8.0 & 14.7 & 47.4 \\
& 13.8 & 5.0 & 2.9 & 1.9 & 3.3 & 11.0 \\
\hline
\end{tabular}

${ }^{a}$ Grain interior resistivity as reported by Bonanos et $a .^{2}$

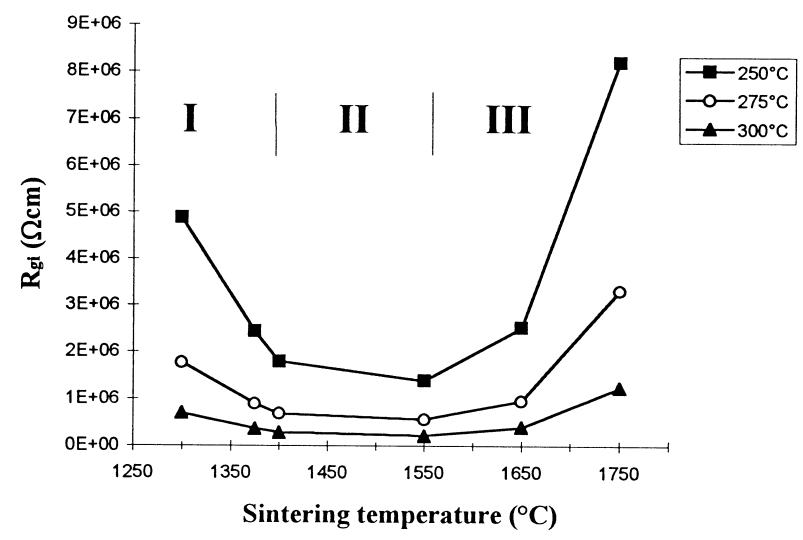

Fig. 3. $R_{\text {gi }}$ at $250-300^{\circ} \mathrm{C}$ as a function of sintering temperature $(1 \mathrm{~h})$, classified into three distinct regions.

is due to individual grains growing larger than the critical grain size (typically $>1 \mu \mathrm{m}$ ) which results in spontaneous transformation to the monoclinic phase on cooling below the thermodynamic transition temperature. For $2.9 \mathrm{Y}-\mathrm{TZP}$ the critical grain size is approximately $1 \mu \mathrm{m}$ but can vary according to composition, stabilising agent and density. Table 1 also show values for $R_{\mathrm{gi}}$ as measured by Bonanos et al., ${ }^{2}$ which are slightly lower than the core-shell material. This may be due to the contribution of the high resistivity monoclinic core in the core-shell material, to the overall resistance.

\subsubsection{Variation of grain boundary resistivity with processing temperature}

The variation of grain boundary resistivity $\left(R_{\mathrm{gb}}\right)$ with sintering temperature also consists of three distinct regions as shown in Table 2 and Fig. 4. In region $1\left(<1400^{\circ} \mathrm{C}\right)$ the resistivity decreases rapidly with increasing sintering temperature. This is due to incomplete sintering below $1400^{\circ} \mathrm{C}$ and the material contains constriction resistance components or narrow contacting necks. ${ }^{9}$ There may also be considerable porosity at grain boundaries or triple points. In the temperature range 1400

Table 2. $R_{\mathrm{gb}}(\mathrm{k} \Omega \mathrm{cm})$ for $\mathrm{Y}-\mathrm{TZP}$ materials sintered at various temperatures $(1 \mathrm{~h})$

\begin{tabular}{lcccccc}
\hline & \multicolumn{7}{c}{$\begin{array}{c}\text { Sintering temperature } \\
\left({ }^{\circ} \mathrm{C} \text { for } 1 \mathrm{~h}\right)\end{array}$} \\
\hline $\begin{array}{l}\text { Measurement } \\
\text { temperature } \\
{[\mathrm{T} /(\mathrm{K})]}\end{array}$ & 1300 & 1375 & 1400 & 1550 & 1650 & 1750 \\
\hline 523 & & & & & & \\
548 & 12700 & 5520 & 3400 & 1830 & 2330 & 10900 \\
573 & 4100 & 1810 & 1140 & 654 & 828 & 3880 \\
& 1450 & 658 & 418 & 225 & 307 & 1340 \\
603 & & & & $460-610^{a}$ & & \\
633 & 466 & 215 & 140 & $86 \cdot 1$ & 101 & 510 \\
673 & 166 & $77 \cdot 5$ & $50 \cdot 7$ & $28 \cdot 1$ & $36 \cdot 2$ & 167 \\
723 & $43 \cdot 3$ & $21 \cdot 5$ & $14 \cdot 6$ & $7 \cdot 9$ & $10 \cdot 5$ & $47 \cdot 2$ \\
& $4 \cdot 3$ & $3 \cdot 1$ & $2 \cdot 9$ & $3 \cdot 4$ & $2 \cdot 7$ & $20 \cdot 1$ \\
\hline
\end{tabular}

${ }^{a}$ Grain boundary resistivity as reported by Bonanos et al. ${ }^{2}$ 
$1550^{\circ} \mathrm{C}$ (region II) a slow decrease in $R_{\mathrm{gb}}$ is observed (minimum value at $1550^{\circ} \mathrm{C}$ ). A decrease in the grain boundary resistance in this temperature region has also been reported by Badwal. ${ }^{10}$ Sintering at $1400^{\circ} \mathrm{C}$ or below was said to result in impurities being present between grains. At 1400 $1500^{\circ} \mathrm{C}$ the impurity phase is liquid or less viscous and at high temperatures the impurity phases migrate to triple points so that grain boundaries become 'cleaner'. Above $1650^{\circ} \mathrm{C}$ the value of $R_{\mathrm{gb}}$ increases greatly even though the grain size has increased $(>1 \mu \mathrm{m})$. This is considered to be due to destabilisation and the formation of monoclinic zirconia.

Table 2 also shows measurements on typical $\mathrm{Y}-$ TZP by Bonanos et al. ${ }^{2}$ The grain boundary resistivity is significantly lower for the core-shell material. Further work is required to elucidate whether this is due to the higher purity of the starting powder or as a direct consequence of the core-shell microstructure, which allows a higher chemical concentration of $\mathrm{Y}_{2} \mathrm{O}_{3}$ to be present at the grain boundary.

\subsubsection{Variation of ionic conductivity with temperature}

The variation of conductivity with temperature enables the activation energy for grain interior and grain boundary conduction to be calculated. Conductivity can be described using the Arrhenius equation,

$$
\sigma=\left(\sigma_{o} / T\right) \cdot \exp \left(-\Delta H_{\sigma} / k \cdot T\right)
$$

where,

$$
\begin{array}{ll}
\sigma & =\text { conductivity of the material }\left(\Omega^{-1} \mathrm{~cm}^{-1}\right) \\
\Delta \mathrm{H}_{\sigma} & =\text { activation energy for conduction }(\mathrm{eV}) \\
T & =\text { Temperature }(\mathrm{K}) \\
k & =\text { Boltzmann constant }\left(\mathrm{J} \mathrm{K}^{-1}\right)
\end{array}
$$

From eqn (1), a graph of $\ln (\sigma . T)$ versus $1 / T$ results in a linear graph with a gradient of $\Delta H_{\sigma} / k$

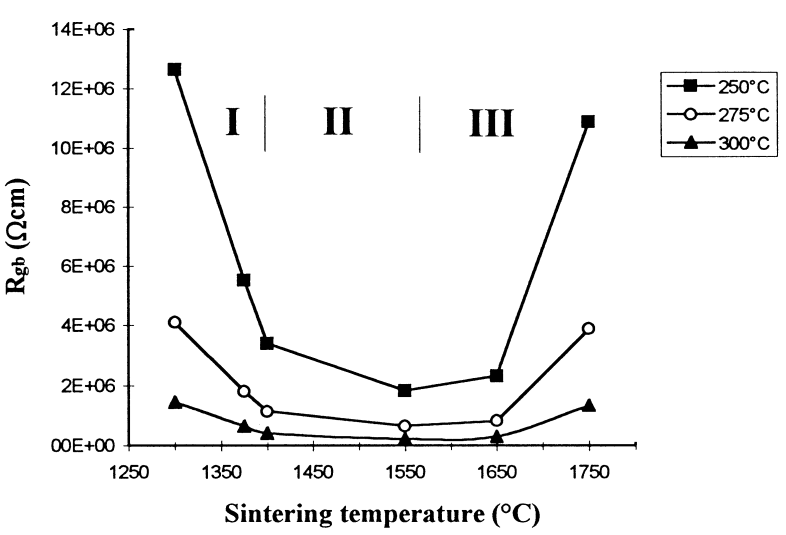

Fig. 4. $R_{\mathrm{gb}}$ at $250-300^{\circ} \mathrm{C}$ as a function of sintering temperature $(1 \mathrm{~h})$, classified in three distinct regions. and an intercept $\ln \left(\sigma_{o}\right)$. Figures 5 and 6 show Arrhenius plots of the variation of grain interior and grain boundary resistivity with temperature. Activation energies calculated for grain interior and grain boundary conductivity are shown in Table 3. No change in slope is observed in the temperature range of $250-450^{\circ} \mathrm{C}$, which indicates a single rate controlling conduction mechanism in this temperature region.

Calculated activation energies are shown in Table 3. The activation energy for grain interior conduction remain constant for Y-TZP material sintered in the temperature range $1300-1550^{\circ} \mathrm{C}$ $\left(\Delta H_{g i}=1.08-1.09 \mathrm{eV}\right.$ and $\Delta H_{g b}=1.15-1.19$ $\mathrm{eV})$. The values are consistent with other reported results on Y-TZP. There is an increase in the grain interior activation energy for the material sintered above $1650^{\circ} \mathrm{C}$, again possibly due to the destabilisation of the tetragonal zirconia. The initial higher grain boundary activation energy measured for material sintered in the temperature range 1300 $1375^{\circ} \mathrm{C}$ may be attributable to incomplete sintering and the presence of porosity.

The fact that the activation energies for grain interior and grain boundary are consistently different

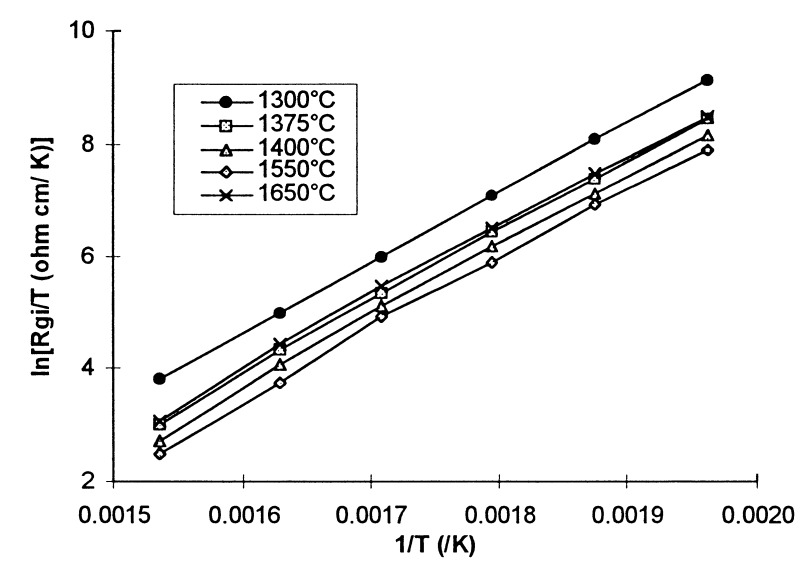

Fig. 5. Arrhenius plot of grain interior resistivity. Minimum $R_{\text {gi }}$ when sintered $1550^{\circ} \mathrm{C} / 1 \mathrm{~h}$.

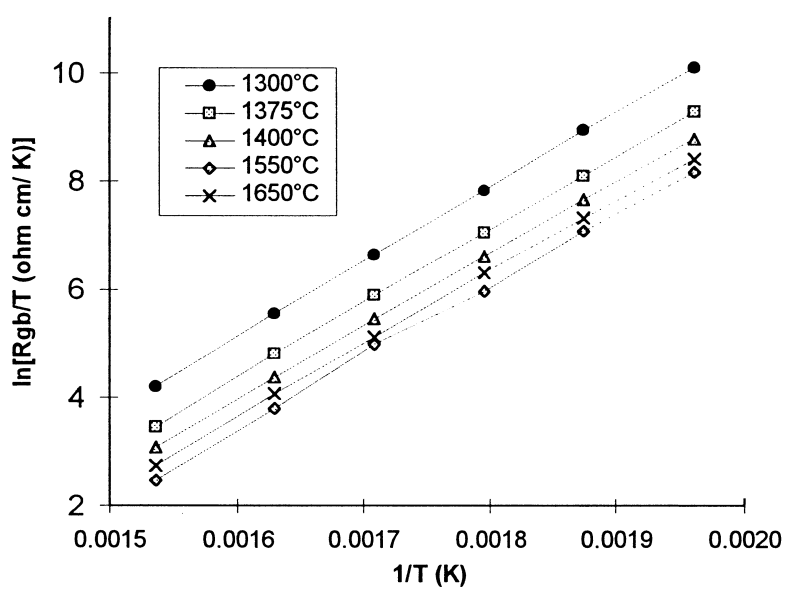

Fig. 6. Arrhenius plot of grain boundary resistivity. Minimum $R_{\mathrm{gb}}$ when sintered $1550^{\circ} \mathrm{C} / 1 \mathrm{~h}$. 
Table 3. Grain interior $\left(\Delta H_{\mathrm{gi}}\right)$ and grain boundary $\left(\Delta H_{\mathrm{gb}}\right)$ activation energies

\begin{tabular}{lcccc}
\hline $\begin{array}{l}\text { Sintering } \\
\text { temperature } \\
\left({ }^{\circ} \text { C for } 1 \mathrm{~h}\right)\end{array}$ & $\begin{array}{c}\Delta \mathrm{H}_{g i} \\
(\mathrm{eV})\end{array}$ & $\begin{array}{c}\Delta \mathrm{H}_{g b} \\
(\mathrm{eV})\end{array}$ & $\begin{array}{c}\sigma_{o(g i)}\left(\Omega^{-1}\right. \\
\left.\mathrm{cm}^{-1} \mathrm{~K}\right)\end{array}$ & $\begin{array}{c}\sigma_{o(g)}\left(\Omega^{-1}\right. \\
\left.\mathrm{cm}^{-1} \mathrm{~K}\right)\end{array}$ \\
\hline 1300 & 1.08 & 1.19 & $2.80 \times 10^{6}$ & $1.09 \times 10^{7}$ \\
1375 & 1.09 & 1.17 & $7.40 \times 10^{6}$ & $1.70 \times 10^{7}$ \\
1400 & 1.09 & 1.15 & $8.40 \times 10^{6}$ & $1.84 \times 10^{7}$ \\
1550 & 1.09 & 1.15 & $1.23 \times 10^{7}$ & $3.13 \times 10^{7}$ \\
1650 & 1.13 & 1.15 & $1.3 \times 10^{7}$ & $3.08 \times 10^{7}$ \\
1750 & 1.13 & 1.15 & $1.3 \times 10^{7}$ & $3.08 \times 10^{7}$ \\
\hline
\end{tabular}

implies that the 'brick layer' model is appropriate for this material, i.e. the material has a continuous grain boundary phase and no 'easy paths'. Fully or partially stabilised zirconia often has similar $\Delta H_{\mathrm{gi}}$ and $\Delta H_{\mathrm{gb}}$ activation energies attributed to the formation of discrete grain boundary phases so that a "partial blocking model' is considered more appropriate.

\subsection{Thermal shock resistance}

Figure 7 is a transmission electron micrograph (TEM) of the Y-TZP material prepared using the yttria coated zirconia powder. Grains consist of an outer core containing a high concentration of yttria which stabilises the zirconia to the tetragonal phase. It is this region that imparts the high ionic conductivity. The low diffusion rate of yttria at the sintering temperature results in less yttria having diffused into the central core of the grains and there the zirconia remains unstabilised in the monolinic form (note twinning is the grain core of Fig. 7). It is expected that the presence of monoclinic phase would improve the poor thermal shock resistance of the Y-TZP material due to the generation of microcracking, a common method of improving thermal shock resistance. ${ }^{11}$

Thermal shock data for Y-TZP ceramics sintered at different temperatures are shown in Fig. 8.

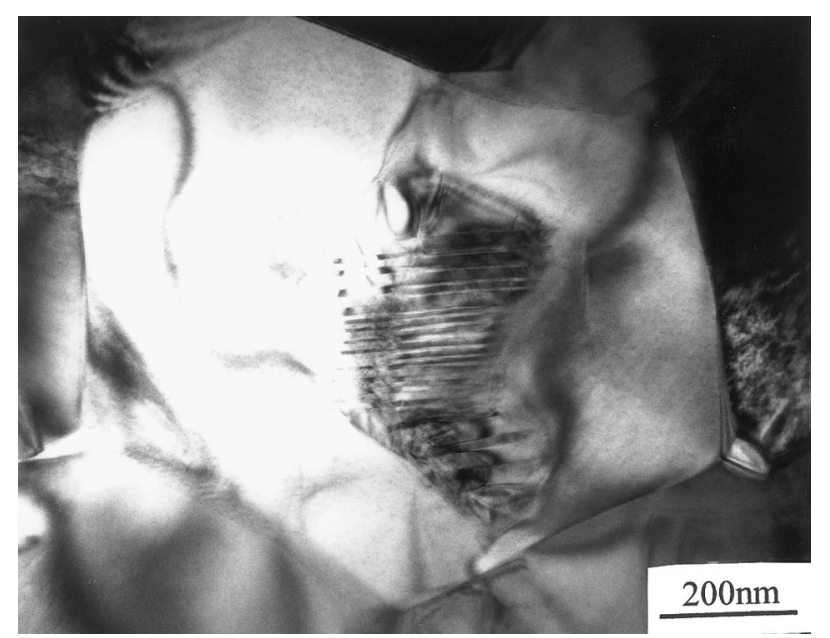

Fig. 7. TEM of core-shell microstructure in yttria coated zirconia.

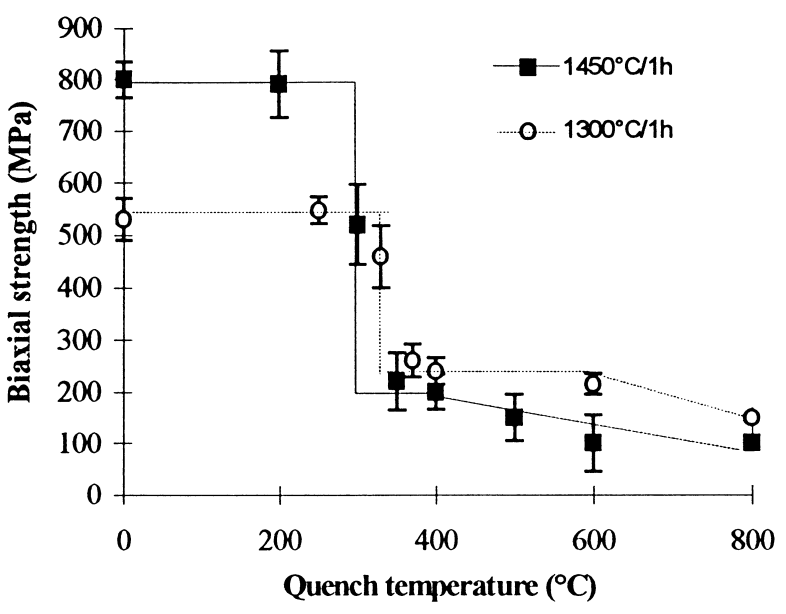

Fig. 8. Thermal shock data for Y-TZP ceramics.

The graph shows a critical $\Delta T_{\mathrm{c}}$, whereby strength decreases significantly in the temperature range $300-350^{\circ} \mathrm{C}$. As with many fine grained ceramics, there is a region of retained strength when $\Delta T$ is slightly greater than $\Delta T_{\mathrm{c}}$. A further increase in $\Delta T$ results in a decrease of retained strength. This is due to the large thermal strain energy required to initiate a crack from small defects. It should be noted that the initial formation of cracks will have a deleterious affect on the ionic conductivity. The critical quenching temperature is somewhat higher than values reported for thermal shock measurements on other Y-TZP ceramics which, range from 250 to $275^{\circ} \mathrm{C}^{12,13}$

\section{Conclusions}

A Y-TZP ceramic with a core-shell microstructure has been examined in an attempt to produce a sensor material with high ionic conductivity and good thermal shock resistance. Impedance spectroscopy has be used to characterise the ionic conductivity in Y-TZP material. Activation energies for grain boundary and grain interior conduction have been calculated and are sufficiently different to indicate that the 'brick layer' model is appropriate for this material. This implies that the microstructure consists of a continuous grain boundary phase and no easy paths for conduction.

The grain interior and grain boundary resistivities have been optimised with regard to processing conditions. $R_{\mathrm{gi}}$ is decreased by generating complete stabilisation of the zirconia to the higher conducting tetragonal phase. $R_{\mathrm{gi}}$ is slightly higher than for conventional Y-TZP, possibly due to the monoclinic core (Fig. 7).

Due to a critical grain size in TZP materials, $R_{\mathrm{gb}}$ cannot be decreased by increasing the grain size as this leads to destabilisation. For this reason, 
attempts to decrease $R_{\mathrm{gb}}$ have involved producing high purity powders. Grain boundary measurements on the core-shell coated zirconia have revealed significantly lower $R_{\mathrm{gb}}$ values than those reported in the literature. Further work is required to elucidate whether this is due to the high purity of the starting powder or as a direct consequence of the core-shell microstructure.

In conjunction with the TZP material demonstrating a high ionic conductivity the thermal shock resistance measurements have also revealed a slight increase in the critical $\Delta T_{\mathrm{c}}$ when compared to other TZP ceramics. Both improvements are attractive features for enhanced electrolyte performance in solid state electrolyte applications such a sensors or fuel cells.

\section{Acknowledgements}

The authors would like to acknowledge EPSRC for funding of this project and Dr G. P. Dransfield of Tioxide Specialties Ltd, Billingham, UK for providing the powder.

\section{References}

1. Steele, B. C. H., Drennan, J., Slotwinski, R. K., Bonanos, N. and Butler E. P., Factors affecting the performance of oxygen monitors, Science and Technology of Zirconia, Advances in Ceramics, Vol. 3, ed. H. Heuer and L. W. Hobbs. The American Ceramic Society Columbus, OH, 1981, p. 286.

2. Bonanos, N., Slotwinski, R. K., Steele, B. C. H. and Butler, E. P., J. Mat. Sci. Let., 1984, 3, 245.

3. Keizer, K., Van Hemert, M., Winnubst, A. J. A., Van de Graaf, M. A. and Burggraaf, A., Preparation, microstructure and electrical properties of yttria doped tetragonal zirconia, J. 13th International Conference on Science of Ceramics, J. de Physique, 1986, 1, C1-789-793.

4. Badwal, S. P. S. and Drennan, J., J. Mat. Sci., 1989, 24, 88.

5. Bauerle, L. E., J. Phys. Chem. Solids., 1969, 30, 2657.

6. Dransfield, G. P., Jennet, T. A. and Williarns, E. J. A., Brit. Ceram. Soc. Proc., 1996, 55, 283.

7. Lawson, S., Gill, C. and Dransfield, G. P., Key. Eng. Mat., 1995, 113, 207.

8. Armstrong, T. R. and Buchanan, R. C., J. Am. Ceram. Soc., 1990, 755, 1268.

9. Irvine, J. T. S., Sinclair, D. C. and West, A. R., Adv. Mat., 1990, 2, 132.

10. Badwal, S. P. S. and Drennan, J., J. Mat. Sci., 1987, 7, 3231.

11. Hasselman, D. P. H., J. Am. Ceram. Soc., 1969, 52, 600

12. Ishitsuka, M. Sato, T., Endo, T. and Shimada, M., $J$. Mat. Sci. Lett., 1989, 24, 4057

13. Ishitsuka, M., Sato, T., Endo, T. and Shimada, M., J. Am. Ceram. Soc., 1987, 70, C-342. 